CLINICAL STUDY

\title{
Birth weight influences long-term catch-up growth and height prognosis of GH-deficient children treated before the age of 2 years
}

Malgorzata Wasniewska, Teresa Arrigo, Mariangela Cisternino ${ }^{1}$, Francesco De Luca, Lucia Ghizzoni ${ }^{2}$, Mohamad Maghnie ${ }^{1}$, Mariella Valenzise and Filippo De Luca

Institutes of Pediatrics, Universities of Messina, ${ }^{1}$ Pavia and ${ }^{2}$ Parma, Italy

(Correspondence should be addressed to F De Luca, Istituto di Clinica Pediatrica, Policlinico Universitario, 98123 Messina, Italy; Email: fdeluca@unime.it)

\begin{abstract}
Objective: To investigate which pretreatment variables most significantly affect long-term growth response to GH therapy in children with apparently idiopathic GH deficiency (GHD) treated from a similar and very young age (less than 2 years), for the same period (7 years) and with the same therapeutic protocol.

Design and methods: Twelve children with either isolated GHD or multiple pituitary hormone deficiency were treated with biosynthetic human $\mathrm{GH}(0.7 \mathrm{IU} / \mathrm{kg}$ per week) and were examined every 6 months. Height measurements were performed by Harpenden stadiometers. Bone age was evaluated every 12 months.

Results: The onset of therapy was followed in all patients by an important height gain, which attained its zenith during the first year of treatment and became progressively less evident during the next 4 years. Cumulative height gain was $3.0 \pm 1.7$ SDS. Thanks to the therapy, at the end of the 7 -year treatment period, average height in the entire series was not significantly far from mean target height (TH) $(-0.7 \pm 1.3$ vs $-0.3 \pm 0.4$ SDS $)$ and average predicted height $(\mathrm{PH})(-0.2 \pm 1.4$ SDS $)$ was very close to $\mathrm{TH}$. A stepwise regression analysis showed that both catch-up growth under therapy and $\mathrm{PH}$ at the end of the 7-year treatment period were positively influenced by birth weight (BW).

Conclusions: a) Our 7-year prospective study on GHD infants treated with GH from less than 2 years of age confirmed the importance of early diagnosis and treatment of GHD in childhood. b) The influence of BW on growth response to GH therapy in GHD children persists over time, at least when treatment is begun from less than 2 years of age.
\end{abstract}

European Journal of Endocrinology 142 460-465

\section{Introduction}

The long-term growth response to growth hormone (GH) therapy in GH-deficient (GHD) children is known to be mainly conditioned by both pretreatment and treatment factors including: pretreatment height deficit (HD), treatment duration, target height (TH) and mean frequency of injections (1).

Also, birth weight (BW) has been recently demonstrated to affect the initial growth response to $\mathrm{GH}$ treatment in GHD children (2). Whether the influence of $\mathrm{BW}$ persists during the next years of GH therapy, however, remains to be seen.

The aim of this prospective 7-year study was to investigate which pretreatment variables most significantly affect the long-term growth response to $\mathrm{GH}$ therapy in children with apparently idiopathic GHD treated from a similar and very young age (less than 2 years), for the same period ( 7 years) and with the same therapeutic protocol.

\section{Patients and methods}

\section{Patients}

Our study population included 12 children ( 7 boys, 5 girls; mean age $1.5 \pm 0.5$ years; range $0.4-1.9$ ) with either isolated GHD (IGHD) or multiple pituitary hormone deficiency (MPHD), who were enrolled for this investigation on the basis of strict inclusion and exclusion criteria, in order to obtain a homogeneous series of patients with non-tumoral, non-hereditary and apparently idiopathic pure GHD.

Inclusion criteria were : a) HD of at least 2 standard deviation scores (SDS); b) peak GH response to two 
pharmacological tests (insulin and clonidine or arginine) of less than $10 \mu \mathrm{g} / \mathrm{l}$; c) chronological age (CA) at GH treatment onset lower than 2 years.

Exclusion criteria were: a) evidence of hypothalamopituitary neoplasias at magnetic resonance imaging; b) family history of hypopituitarism; c) consanguinity of patients' parents; d) known immunodeficiency or history of recurrent infections in GHD males; e) abnormal prolactin secretion in patients with both $\mathrm{GH}$ and thyrotropin (TSH) deficiency.

The auxological and endocrine features of our patients at the start of $\mathrm{GH}$ treatment, as well as their auxological data at birth, are analytically reported in Table 1.

\section{Study design}

All patients were treated with biosynthetic human $\mathrm{GH}$ by daily subcutaneous injections at the same dose $(0.7 \mathrm{IU} / \mathrm{kg}$ per week) and for the same period ( 7 years). MPHD children received replacement therapy as needed (L-thyroxine up to $5 \mu \mathrm{g} / \mathrm{kg}$ per day and/or hydrocortisone up to $10 \mathrm{mg} / \mathrm{m}^{2}$ per day).

All children were examined every 6 months throughout the entire study period in order to: a) check their compliance and their clinical and growth response to therapy; b) adjust hormone substitutive doses to weight progression.

Bone age (BA) was evaluated every 12 months. The study design was approved by our Hospitals' Ethics Committees.

\section{Methods}

Height measurements of the patients and their parents were performed by either supine or standing Harpenden stadiometers (Zamboni, Bologna, Italy). Height SDS were calculated according to the standards by Sempè et al. (3). Left hand radiographs for BA evaluation were estimated according to the method of Greulich and Pyle (4). Prediction of adult height at the time of the last check ( 7 years after the start of $\mathrm{GH}$ treatment) was based on the method assessed by Bayley and Pinneau (5). TH was calculated on the basis of parents' measured heights according to Tanner et al. (6) and assessed as SDS by French standards (3).

GH assays were performed separately at each center, using commercial kits based on polyclonal antibodies. Thyroid and adrenal functions were evaluated in all patients leading to a classification of either IGHD or MPHD. The pituitary-thyroid axis function was investigated by evaluating serum thyroxine (T4), free $\mathrm{T} 4$, triiodothyronine (T3), free T3 and TSH baseline serum concentrations and by a thyrotropin-releasing hormone (TRH) test $\left(200 \mu \mathrm{g} / \mathrm{m}^{2}\right.$ i.v. $)$; reduced free T4 values $(<12 \mathrm{pmol} / \mathrm{l})$ with a delayed TSH response after injection of TRH (i.e. a larger quantity of TSH after $60 \mathrm{~min}$ than between $20-60 \mathrm{~min}$ ) was considered to indicate hypothalamic hypothyroidism. Adrenal function was estimated as basal serum cortisol (normal values $265-365 \mathrm{nmol} / \mathrm{l}$ ) and corticotropin (normal values $2.2-17.6 \mathrm{~mol} / \mathrm{l}$ ) concentrations at $08.00 \mathrm{~h}$, and as the serum cortisol response to insulin-induced hypoglycemia (normal response was defined as an increase above baseline cortisol concentrations of more than $190 \mathrm{nmol} / \mathrm{l}$ or an increase to a peak value greater than $550 \mathrm{nmol} / \mathrm{l})$. Diagnosis of gonadotropin deficiency was made on clinical grounds only in newborns with both microphallus and cryptorchidism.

Data concerning BW, birth length (BL) and gestational age were obtained from patients' hospital records. The SDS for BW and BL with respect to gestational age were calculated according to the standards of Sempè et al. (3).

\section{Statistics}

The data are expressed as means \pm S.D. The SDS for height were calculated as height minus mean height for normal subjects of the same age and sex divided by S.D. of height for normal subjects of the corresponding age and sex.

Comparisons between groups were made by either Student's paired t-test or Wilcoxon test, as appropriate.

The following pretreatment variables were evaluated in a stepwise regression analysis model: BW, BL, GH peak; $\mathrm{CA}$ and $\mathrm{BA}$ at the start of $\mathrm{GH}$ treatment; and difference between TH and pretreatment height. Stepwise regression analysis was used to determine which of these factors most significantly affected either the total height gain under GH therapy or predicted height $(\mathrm{PH})$ at the end of 7-year $\mathrm{GH}$ treatment.

\section{Results}

\section{Patients' endocrine features}

$\mathrm{GH}$ peak in the whole cohort ranged from 0.5 to $9.2 \mu \mathrm{g} / \mathrm{l}$ and 8 patients $(67 \%)$ exhibited a $\mathrm{GH}$ peak $<3 \mu \mathrm{g} / \mathrm{l}$. Seven patients $(58 \%)$ had IGHD and five $(42 \%)$ had MPHD: two with anterior panhypopituitarism (Nos. 9, 12 in Table 1) and three with combined GH-TSH deficiency (Nos. 1,3,11).

\section{Auxological data at birth and at GH treatment onset}

The mean BW and BL in the entire series were respectively $-1.0 \pm 1.2$ SDS and $-2.0 \pm 1.0$ SDS. Either three $(25 \%)$ or eight $(67 \%)$ children would have been classed as small for gestational age on the basis of either BW or BL respecively.

At the time of $\mathrm{GH}$ treatment onset, BA was significantly delayed with respect to $C A(P<0.0005)$.

$\mathrm{HD}$ in the entire series ranged from -2.0 to -7.1 SDS. The resultant height was, on average, significantly 
Table 1 Baseline characteristics of our patients prior to commencement of GH therapy and their height after 7 years of GH treatment: individual and average data.

\begin{tabular}{|c|c|c|c|c|c|c|c|c|}
\hline Patient & $\begin{array}{c}\text { BW } \\
\text { (SDS) }\end{array}$ & $\begin{array}{c}\text { CA } \\
\text { (years) }\end{array}$ & $\begin{array}{c}\text { BA } \\
\text { (years) }\end{array}$ & $\begin{array}{c}\mathbf{H 1} \\
(\mathrm{SDS})\end{array}$ & $\begin{array}{c}\mathrm{H} 2 \\
(\mathrm{SDS})\end{array}$ & $\begin{array}{c}\text { TH } \\
\text { (SDS) }\end{array}$ & $\begin{array}{c}\text { GH peak } \\
(\mu \mathrm{g} / \mathrm{l})\end{array}$ & $\begin{array}{c}\text { Hormone } \\
\text { deficiencies }\end{array}$ \\
\hline 1 & -2.9 & 1.8 & 1.0 & -2.4 & -1.6 & 0.2 & 7.0 & MPHD \\
\hline 2 & -2.5 & 1.8 & 0.5 & -2.3 & -1.5 & -0.2 & 5.3 & IGHD \\
\hline 3 & -2.0 & 0.4 & 0.1 & -7.0 & -1.0 & -0.8 & 0.5 & MPHD \\
\hline 4 & -1.8 & 1.7 & 0.2 & -3.1 & -0.7 & -0.1 & 9.2 & IGHD \\
\hline 5 & -1.3 & 1.9 & 1.3 & -2.8 & -1.9 & -0.8 & 2.4 & IGHD \\
\hline 6 & -1.1 & 1.7 & 1.0 & -4.8 & -0.2 & 0.4 & 1.1 & IGHD \\
\hline 7 & -0.9 & 1.7 & 0.5 & -5.6 & -1.5 & -0.4 & 0.5 & IGHD \\
\hline 8 & -0.6 & 0.5 & 0.1 & -2.0 & -0.2 & -0.4 & 1.4 & IGHD \\
\hline 9 & -0.3 & 1.9 & 2.0 & -2.0 & 0.9 & -0.2 & 2.5 & MPHD \\
\hline 10 & 0.3 & 1.6 & 0.5 & -2.3 & 0.3 & 0.2 & 1.8 & IGHD \\
\hline 11 & 0.7 & 1.6 & 0.3 & -7.1 & -3.2 & -0.7 & 6.2 & MPHD \\
\hline 12 & 1.0 & 1.2 & 0.1 & -2.8 & 1.3 & -0.2 & 0.8 & MPHD \\
\hline Mean \pm S.D. & $-1.0 \pm 1.2$ & $1.5 \pm 0.5$ & $0.6 \pm 0.6$ & $-3.7 \pm 1.9$ & $-0.7 \pm 1.9$ & $-0.3 \pm 0.4$ & $3.2 \pm 2.8$ & \\
\hline
\end{tabular}

$\mathrm{H} 1=$ height at the onset of therapy, $\mathrm{H} 2=$ height after 7 years of $\mathrm{GH}$ treatment.

lower than $\mathrm{TH} \quad(-3.7 \pm 1.9$ vs $-0.3 \pm 0.4$ SDS $P<0.005)$.

\section{Individual auxological data at the end of the 7-year treatment period}

Almost all the children (eleven out of twelve) attained a current height within normal range (mean \pm 2 SDS) and only one patient (No. 11 of Table 1) was still abnormally short (-3.2 SDS). It is to be underlined, however, that pretreatment HD of this patient was -7.1 SDS, which means that his height gain during the entire treatment period was 3.9 SDS. Six patients (Nos. $4,6,8,9,10,12$ of Table 1) reached a current height above -1.0 SDS and four (Nos. 8, 9, 10, 12) were able to achieve their target percentile.

\section{Average auxological data under GH treatment}

The onset of therapy was followed in all patients by an important height gain, which attained its zenith during the first year of treatment $(1.3 \pm 1.0$ SDS, $P<0.0025)$ and became progressively less evident during the next 4 years: $0.9 \pm 0.9$ SDS $(P<0.005)$ from the first to the third year and $0.6 \pm 0.5$ SDS from the third to the fifth year $(P<0.0025)$. During the last 2 years of treatment (from the fifth to the seventh year) height gain $(0.7 \pm 1.3 \mathrm{SDS})$ did not achieve a statistical relevance. The cumulative height gain during the 7 years of $\mathrm{GH}$ treatment was $3.0 \pm 1.7$ SDS.

At the end of the 7-year treatment period average height in the entire series was not significantly far from mean TH $(-0.7 \pm 1.3$ vs $-0.3 \pm 0.4$ SDS $)$ and average $\mathrm{PH}$ was very close to $\mathrm{TH}(-0.2 \pm 1.4$ vs $-0.3 \pm 0.4$ SDS) (Fig. 1).

During the first year of therapy, height gain was not accompanied by an acceleration of $\mathrm{BA}$, as revealed by the stable CA:BA ratio (Fig. 2). A significant acceleration of bone maturation was recorded after the first year of therapy and persisted until the fifth year. At the end of the 7-year treatment period CA:BA ratio was very significantly lower than that calculated at entry (Fig. 2); however, BA was still delayed with respect to $\mathrm{CA}(7.1 \pm 1.8$ vs $8.7 \pm 0.6, P<0.0025)$ and no patient exhibited clinical signs of starting puberty.

\section{Stepwise regression analysis}

In the entire cohort, when the other variables were excluded, height gain during the whole study period was independently and positively influenced by only two pretreatment factors: a) difference between $\mathrm{TH}$ and pretreatment height $(\mathrm{F}=13.56, P<0.005)$; b) BW $(\mathrm{F}=8.80, P<0.02)$.

$\mathrm{PH}$ at the end of $\mathrm{GH}$ treatment period was found to be positively influenced by $\mathrm{BW}(\mathrm{F}=7.03, P<0.05)$ and negatively by: a) difference between $\mathrm{TH}$ and pretreatment height $(\mathrm{F}=4.18, P<0.1)$; b $) \mathrm{BA}$ at the onset of GH therapy $(\mathrm{F}=55.43, P<0.001)$.

\section{Discussion}

The most important findings suggested by the analysis of our data concern the factors which affected the auxological long-term response to $\mathrm{GH}$ treatment of our patients.

According to recent retrospective studies on final height (FH) (7-9) or near-adult height (10) in GHD patients, the long-term growth response to GH therapy is most significantly influenced by treatment variables, such as duration of treatment, total GH dose and injection frequency (positive correlations). Among pretreatment variables the one with the greatest identified influence on long-term growth response seems to be age at therapy onset: the younger the patient the greater the FH. Nevertheless, because 


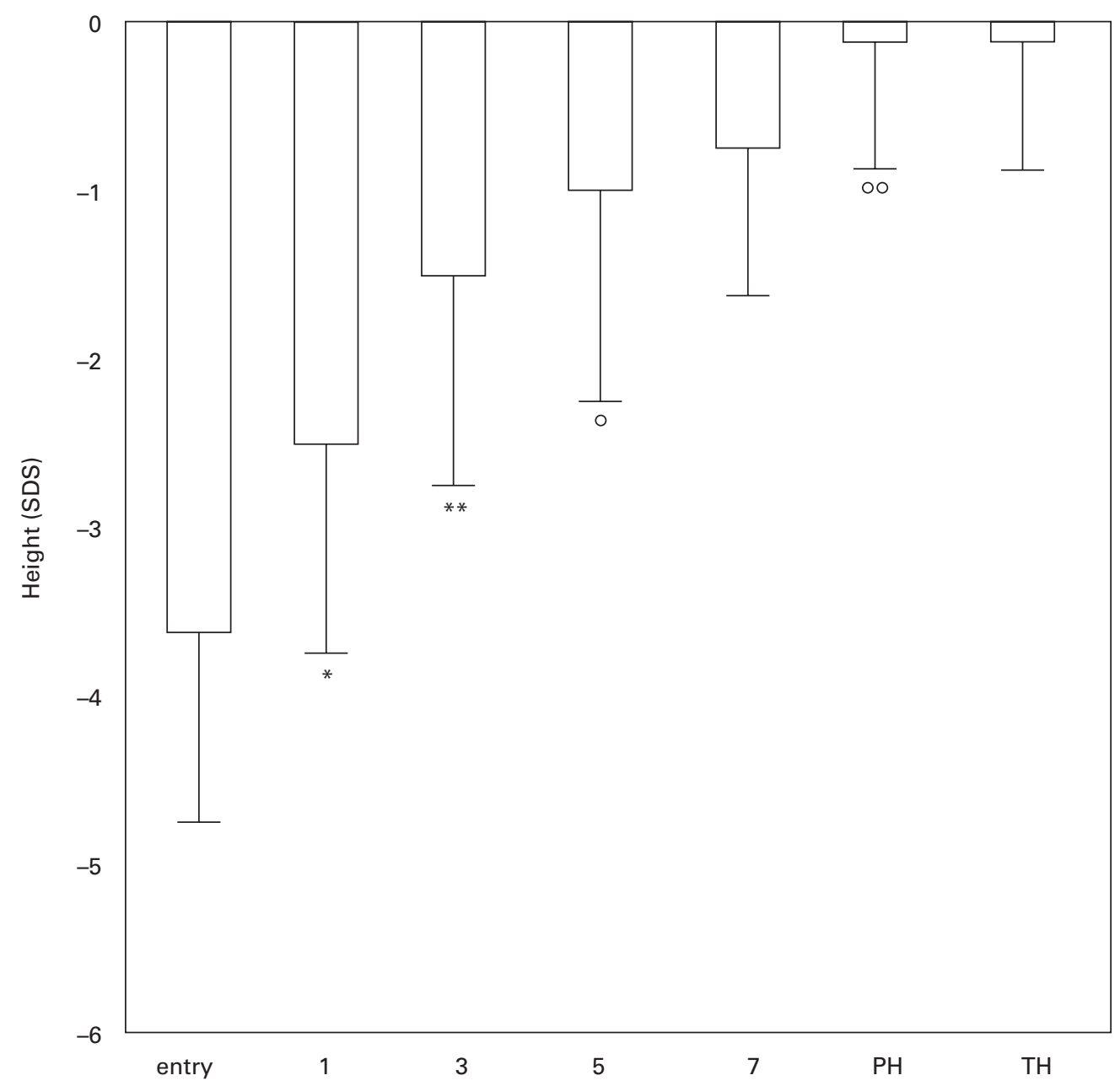

Figure 1 Height SDS at entry, during the first 7 years of treatment, adult height predicted at the seventh year of therapy $(\mathrm{PH})$ and target height (TH) of the twelve patients included in our series. ${ }^{\star} P<0.0025$ vs entry; ${ }^{* \star} P<0.005$ vs first year; ${ }^{\circ} P<0.0025$ vs third year; ${ }^{\circ} P<0.05$ vs seventh year.

treatment duration and age at therapy start are highly correlated, the direct influence exerted by age on height outcome is hard to evaluate.

Other pretreatment factors which have been reported to possibly affect the long-term auxological effects of GH therapy in GHD children are: mid-parental height and severity of GHD (8), pretreatment height and BA delay at treatment onset (10).

However, the role played by pretreatment variables in conditioning long-term growth response to GH therapy seems to be less evident and more controversial with respect to that played by treatment factors.

In the present prospective study we took into consideration a very homogeneous population consisting only of patients with pure idiopathic GHD, of a very similar CA, treated with the same therapy protocol and for the same period. This study design gave us the possibility of analyzing the pretreatment factors which are able to affect the long-term growth response to $\mathrm{GH}$ therapy of GHD infants when the interference of the most important treatment variables (treatment duration, injection frequency, total GH dose) is excluded.

BW has been recently reported to be able to influence the first year auxological response to $\mathrm{GH}$ replacement in IGHD children (2). According to our data, this influence persists over time, at least for a 7-year period. Regarding this point our conclusions differ from the ones reported by Rappaport et al. (11), who adopted a study protocol very close to the ours in a 5-year prospective study of GHD children treated with $\mathrm{GH}$ before the age of 3 years. According to their data, the only variable that influenced height gain under therapy was pretreatment height (11). In our series, however, the influence exerted by BW on subsequent growth 


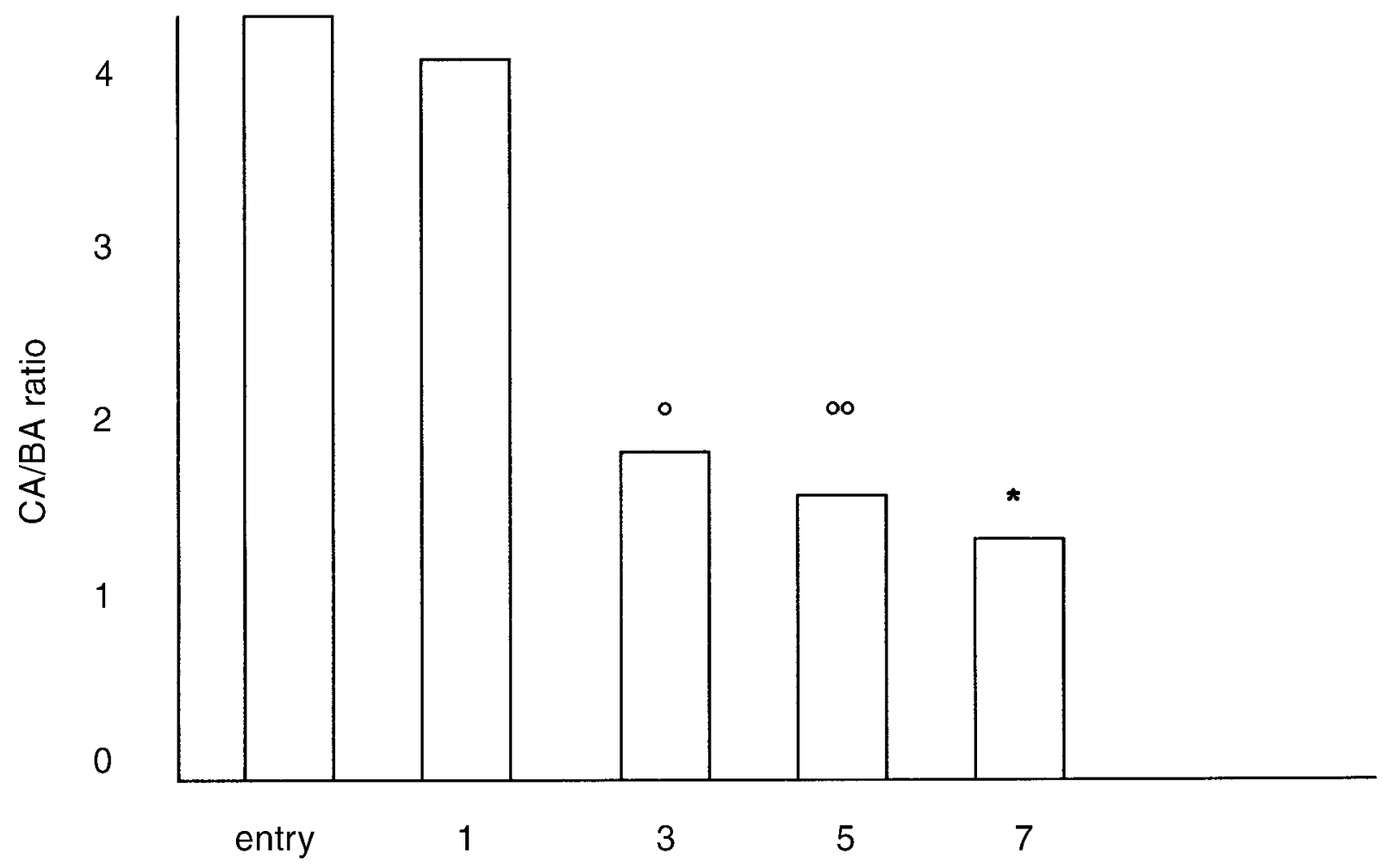

Figure 2 Chronological age/bone age (CA/BA) ratio at entry and during the first 7 years of treatment in the twelve patients included in our series. ${ }^{\circ} P<0.01 v s$ first year of therapy; ${ }^{\circ} P<0.01 v s$ third year of therapy; ${ }^{*} P<0.0025$ vs entry.

response to therapy was statistically relevant not only in terms of height gain but also in terms of $\mathrm{PH}$ at the end of treatment period. Our data, therefore, seem to substantiate the relevance of fetal growth in programming future development and long-term growth response to $\mathrm{GH}$ treatment in GHD children, at least provided that therapy is started when younger than two years of age and that the conventional hormone substitutive doses are used.

In the present study, height gain under therapy and $\mathrm{PH}$ at the end of the 7-year period were either positively or negatively influenced, respectively, by the difference between $\mathrm{TH}$ and pretreatment height.

According to our results the patients with the greatest difference between $\mathrm{TH}$ and pretreatment stature were candidates for the most significant height gain under treatment: the smaller the infants in relation to parental size, the better their growth response to therapy. Nevertheless, in spite of the better catch-up growth during treatment period, they were still disadvantaged in terms of $\mathrm{PH}$ at the end of the 7-year treatment.

In our series, height gain under therapy was not significantly affected by other variables, whereas $\mathrm{PH}$ was influenced to a very relevant degree by pretreatment BA: the lower the BA at therapy start, the higher the $\mathrm{PH}$ at the end of the 7-year follow-up. Since prediction of $\mathrm{FH}$ is based on $\mathrm{BA}$ and considering the acceleration of bone maturation which followed the onset of therapy in our patients, it is understandable that the ones with the lowest pretreatment BA were advantaged in terms of $\mathrm{PH}$.

In the entire series, our patients' current heights after 7-years of treatment were generally within normal range and only one child, in spite of a very important height gain, remained abnormally short. Moreover, their average $\mathrm{PH}$ at the end of treatment period (before puberty onset) was very close to TH.

The overall pattern of catch-up growth observed in our patients demonstrates a sustained and significant growth response to $\mathrm{GH}$ treatment during the first 5 years, with a further slight recovery during the subsequent 2 years. Such a pattern of growth response could suggest the advisability of increasing GH doses after the fifth year of therapy. Nevertheless, the significant acceleration of bone maturation which was recorded between the first and the fifth year of therapy raises many doubts regarding the convenience of such a therapeutical strategy.

In conclusion, our 7-year prospective study on GHD infants treated with $\mathrm{GH}$ from less than two years of age has confirmed the conclusions of other recent prospective (11) and retrospective (12-15) reports emphasizing the importance of early diagnosis and 
treatment of GHD in childhood. Moreover it has demonstrated that the influence of $\mathrm{BW}$ on growth response to $\mathrm{GH}$ therapy in GHD children persists over time, at least when treatment is begun from less than two years of age.

\section{References}

1 Prince DA \& Ranke MB. Final height following growth hormone treatment. In Progress in Growth Hormone Therapy - 5 Years of KIGS, pp 129-144. Eds MB Ranke \& R Gunnarsson. Mannheim: J \& J Verlag, 1994.

2 Achermann JC, Hamdani K, Hindmarsh PC \& Brook CGD. Birth weight influences the initial response to growth hormone treatment in growth hormone-insufficient children. Pediatrics $1998102342-345$.

3 Sempè M, Pedron G \& Roy-Pernot MP. Auxologie, Methode et Sèquences. Paris: Theraplix, 1997.

4 Greulich WW \& Pyle SI. Radiographic Atlas of Skeletal Development of the Hand and Wrist, edn 2. Stanford CA: Stanford University Press, 1995.

5 Bayley N \& Pinneau SR. Tables for predicting adult height from skeletal age: revised for use with the Greulich-Pyle hand standards. Journal of Pediatrics 40 423-441.

6 Tanner JM, Goldstein H \& Whitehouse RH. Standards for children's heights at age 2-9 years allowing for height of parents. Archives of Disease of Childhood 1970 45 755-762.

7 MacGillivray MH, Blethen SL, Buchlis JG, Clopper RR, Sandberg DE \& Conboy TA. Current dosing of growth hormone in children with growth hormone deficiency: how physiologic? Pediatrics 1998102 527-530.

8 Cutfield W, Lindberg A, Albertsson-Wikland K, Chatelain P, Ranke MB \& Wilton P. Final height in idiopathic growth hormone deficiency: the KIGS experience. Acta Paediatrica 1999 $872-75$.

9 Hintz RL. Final height of growth hormone-treated patients with growth hormone deficiency: the North American experience. Acta Paediatrica 19998 70-71.

10 Blethen SL, Baptista J, Kuntze J, Foley T, La Franchi S \& Johanson A. Adult height in growth hormone (GH)-deficient children treated with biosynthetic GH. Journal of Clinical Endocrinology and Metabolism 199782 418-420.

11 Rappaport R, Mugnier E, Limoni C, Crosnier H, Czernichow P, Leger J et al. A 5-year prospective study of growth hormone (GH)-deficient children treated with $\mathrm{GH}$ before the age of 3 years. Journal of Clinical Endocrinology and Metabolism 199782 452-456.

12 Arrigo T, De Luca F, Bernasconi S, Bozzola M, Cavallo L, Crisafulli $\mathrm{G}$ et al. Catch-up growth and height prognosis in early treated children with congenital hypopituitarism. Hormone Research 199544 26-31.

13 De Luca F, Maghnie M, Arrigo T, Lombardo F, Messina MF \& Bernasconi S. Final height outcome of growth homone deficient patients treated since less than five years of age. Acta Paediatrica $1996851167-1171$.

14 Arrigo T, Bozzola M, Cavallo L, Ghizzoni L, Maghnie M, Messina MF et al. Growth hormone deficient children treated from before two years old fail to catch-up completely within five years of therapy. Journal of Pediatric Endocrinology and Metabolism $19981145-50$.

15 Huet F, Carel JC, Nivelon JL \& Chaussain JL. Long-term results of $\mathrm{GH}$ therapy in GH-deficient children treated before 1 year of age. European Journal of Endocrinology 1999140 29-34.

Received 19 July 1999

Accepted 19 January 2000 